\title{
PARTICIPAÇÃO POPULAR NO CONTROLE DA ADMINISTRAÇÃO PÚBLICA: UM ESTUDO EXPLORATÓRIO
}

Fernando do Nascimento Lock ${ }^{1}$

\section{RESUMO}

O estudo mostra que há várias previsões legais de participação do cidadão na administração pública, a qual ocorre quando o cidadão, sem interesse individual imediato e tendo como objetivo o interesse comum, buscando algo por vias administrativas ou judiciais.

Garantida pelo principio da participação popular, a democracia participativa brasileira, prevê variadas formas de atuação do cidadão na condução política e administrativa do Estado.

A audiência pública sendo o instrumento do princípio da participação popular é garantia constitucional desta participação, conforme previsto na Lei de Responsabilidade Fiscal e no Estatuto da Cidade, o que significa dizer que a sua realização é condição de validade para o processo legislativo que tenha por objeto os Planos, Lei de Diretrizes Orçamentárias e Lei do Orçamento Anual.

Palavras-chave: participação popular, controle da administração pública, democracia participativa, audiência pública

\section{ABSTRACT}

The study shows that there are several legal forecasts of the citizen's participation in the public administration, which happens when the citizen, without immediate individual interest and tends as objective the common interest, looks for something for roads administrative or judicial.

\footnotetext{
${ }^{1}$ Professor Ms. Departamento de Ciências Contábeis. Universidade Federal de Santa Maria
} 
Guaranteed for the begin of the popular participation, the democracy participative Brazilian, foresees varied forms of the citizen's performance in the political and administrative transport of the State.

The public audience being the instrument of the beginning of the popular participation is constitutional warranty of this participation, as foreseen in the Fiscal Responsibility Law and in the City's Statute, the one that means say that his/her accomplishment is validity condition for the legislative process that has for object the Plans, Budget Guidelines Law and Annual Budget Law.

\section{INTRODUÇÃO}

A participação popular enquanto princípio constitucional ocorre quando o cidadão, sem interesse individual imediato, tem como objetivo o interesse comum, buscando algo por vias administrativas ou judiciais. Ou seja, é o direito de participação política, de decidir junto, de compartilhar a administração, opinar sobre as prioridades e fiscalizar a aplicação dos recursos públicos, confirmar, reformar ou anular atos públicos.

Este trabalho propõe-se a tratar de alguns aspectos da legislação pertinente a participação cidadã, no sentido de compartilhar as decisões políticas e administrativas, que é o direito garantido pela constituição, que o cidadão tem, de ser acolhida a sua opinião, é o direito de participar da tomada de decisões. Esta participação é antes de tudo uma questão política, pois depende do amadurecimento da consciência cidadã por parte da população e da vinculação do governante com os ideais democráticos e com a transparência na gestão da coisa pública, através da prática da democracia participativa.

A investigação na literatura disponível teve a intenção de firmar bases teóricas referente à legalidade da participação popular no controle da administração pública, a qual foi realizada através de uma pesquisa bibliográfica, que teve como finalidade o estudo exploratório na concepção de $\mathrm{Gil}^{2}$, com vistas a

\footnotetext{
${ }^{2}$ GIL, Antônio Carlos. Como Elaborar Projetos de Pesquisa. 3 ed. São Paulo: Atlas, 1996.
} 
proporcionar uma maior familiaridade com a questão legal desse tipo de participação, tornando-a assim mais explícita.

Este trabalho está estruturado em mais três seções além desta introdução.

A segunda seção detalha os princípios constitucionais da participação popular. A terceira seção trata da democracia participativa através de audiências públicas. A quarta seção apresenta as conclusões do estudo. A bibliografia utilizada é apresentada ao final do trabalho.

\section{PRINCÍPIO CONSTITUCIONAL DA PARTICIPAÇÃO POPULAR}

A consagração do Estado de direito democrático foi produto da luta da humanidade para derrotar o absolutismo, a Constituição Federal de 1988 também é produto de uma intensa mobilização popular contra o regime militar, que culminou com o movimento das Diretas Já em 1984, garantindo dois anos depois a eleição de um Congresso Nacional com poderes constituintes, que elaborou a "Constituição Cidadã" ${ }^{3}$, onde se encontra positivado o princípio constitucional da participação popular.

Há várias previsões de participação do cidadão na administração pública ${ }^{4}$, mas uma em especial parece ser o fio condutor da assunção da participação

\footnotetext{
${ }^{3}$ Expressão cunhada pelo presidente da Assembléia Nacional Constituinte, deputado Ulisses Guimarães, ao promulga-la em outubro de 1988.

${ }^{4} \mathrm{O}$ art. $5^{\circ}$ (dos direitos e garantias fundamentais), no inciso XIV assegura a todos o acesso à informação; nos incisos XXXIII e XXXIV, garantem o direito de receber informações dos órgãos públicos e o direito de petição, materializando o princípio da publicidade; garante também nos incisos LV e LXIX, o devido processo legal administrativo e o mandado de segurança contra ilegalidade ou abuso de poder de autoridade pública; no inciso LXXIII, garante ainda o controle da conduta dos agentes públicos pelo cidadão através da Ação Popular, e para completar, no $\S 2^{\circ}$ do mesmo artigo, afirma que além destas garantias, não se exclui nenhuma outra decorrente dos princípios adotados pela carta, ou dos tratados internacionais em que o país seja parte, abrindo-se portanto uma infinidade de oportunidades de participação na administração pública. No art. 10, assegura a participação dos trabalhadores e empregadores nos colegiados dos órgãos públicos em que seus interesses profissionais ou previdenciários sejam objeto de discussão. No art. 14, assegura a idéia da soberania popular e o voto direto e secreto de igual valor para todos, prevendo ainda o plebiscito, 0 referendo e a iniciativa popular, instrumentos importantes da democracia participativa. No âmbito municipal, o art. 29, XII, garante participação no planejamento e o art. 31, § $3^{\circ}$, garante a ampla fiscalização das contas. Ao disciplinar os princípios que regem a administração pública o Art. $37, \S 3^{\circ}$, possibilita ainda a criação de outras formas de participação do usuário na administração pública. Há também a possibilidade da participação popular no processo legislativo, através de audiências públicas e reclamações contra atos das autoridades, nas comissões das casas legislativas, previstas no Art. 58, II e IV, bem como a participação diretamente na produção de leis, através da iniciativa popular prevista no Art. 61 , § $2^{\circ}$. Possibilitando a atuação do cidadão enquanto fiscalizador da conduta do administrador, prevê o Art. $74, \S 2^{\circ}$, a possibilidade de denunciar irregularidades ou ilegalidades ao Tribunal de Contas da União. Prevê ainda a participação de cidadãos no Conselho da República, conforme disposto no Art. 89, VII, e a participação de entidades de
} 
popular para a condição de princípio constitucional. É o contido no parágrafo único do art. 10: "Todo o poder emana do povo, que o exerce por meio de representantes eleitos ou diretamente, nos termos desta constituição".

Ao afirmar que o povo "exerce diretamente o poder nos termos da constituição" ${ }^{5}$, não está ela contrapondo o exercício representativo do poder com o exercício direto, mas sim, entregando ao povo a possibilidade de se tornar membro efetivo do controle social da administração pública, tal qual explicita Carrion, ao afirmar que "quando se fala em controle social da administração pública, procura-se sugerir a idéia de um controle ao mesmo tempo político e social. Não apenas um controle de legalidade, mas principalmente um controle de mérito, de eficácia, de conveniência e de oportunidade do ato administrativo" ${ }^{6}$.

Apesar de não utilizar o termo participação a Constituição, fala em democracia representativa e democracia direta, portanto a participação popular é própria do Estado Democrático de Direito ali estabelecido, é decorrência natural deste modelo de Estado, que consagra ainda, implícita ou explicitamente outras previsões de participação popular em diversos setores da vida pública. Não bastasse isso, a previsão está inserta no Título I, Dos Princípios Fundamentais, não deixando nenhuma dúvida sobre a pretensão do constituinte originário.

\subsection{Plebiscitos e referendos}

Aparentemente o plebiscito e o referendo são formas de participação direta que não podem necessariamente ser enumeradas como meios de controle dos atos administrativos, contudo em uma analise mais cuidadosa chega-se a

representação de classe na escolha do quinto constitucional para integrantes dos Tribunais Regionais Federais, Tribunais Estaduais e do Distrito Federal, conforme disciplinado no Art. 94. Disciplina também a participação popular na gestão da atividade de administrar, tais como: dos produtores e trabalhadores rurais no planejamento da política agrícola (Art. 187); dos trabalhadores, empregadores e aposentados nas iniciativas relacionadas à seguridade social (Art. 194, VII); da comunidade em relação às ações e serviços de saúde (198, III); da população através de organizações representativas nas questões relacionadas à Assistência Social (Art. 204, II); a gestão democrática do ensino público (206, VI); da colaboração da comunidade na proteção do patrimônio cultural (Art. 216, § $1^{\circ}$ ); da coletividade na defesa e preservação do meio ambiente (Art. 225); de entidades não governamentais na proteção à assistencial integral à saúde da criança e adolescente (Art. 227, $\S 1^{\circ}$ ) e das comunidades indígenas, inclusive nos lucros, das atividades que aproveitem os recursos hídricos e minerais das suas terras $\left(231, \S 3^{\circ}\right)$

${ }^{5}$ Constituição da República Federativa do Brasil, Art. 50, inciso XXXV.

${ }^{6}$ CARRION, Eduardo Kroeff Machado. Apontamentos de direito constitucional. Porto Alegre: Livraria do Advogado, 1997. pp. 83/84 
conclusão que são elementos tão importantes quanto a famosa Lei de Responsabilidade Fiscal que visam combater a improbidade administrativa e regular as atividades administrativa.

A Constituição Federal prevê expressamente que uma das formas de exercício da soberania popular será através da realização direta de consultas populares, através de plebiscitos e referendos ${ }^{7}$, disciplinando, ainda, que caberá privativamente ao Congresso Nacional autorizar referendo e convocar plebiscitos, salvo, quando a própria Constituição expressamente determinar.

No ordenamento jurídico-constitucional essas duas formas, o plebiscito e o referendo, são vistas como meios similares consultivos da opinião popular nos negócios do Estado e basicamente divergem em virtude do momento de suas realizações.

O plebiscito é uma consulta prévia que se faz aos cidadãos no gozo de seus direitos políticos, sobre determinada matéria, a ser, posteriormente, discutida pelo Congresso Nacional, já o referendo, consiste em uma consulta posterior sobre determinado ato governamental para ratificá-lo, ou no sentido de concederIhe eficácia (condição suspensiva), ou ainda, para retirar-Ihe a eficácia (condição resolutiva).

Bobbio mostra o perigo existente na idéia de cidadão total, quando afirma que:

(...) é evidente que, se por democracia direta se entende literalmente a participação de todos os cidadãos em todas as decisões a eles pertinentes, a proposta é insensata. Que todos decidam sobre tudo em sociedades sempre mais complexas como são as modernas sociedades industriais é algo materialmente impossível. E também não é desejável humanamente, isto é, do ponto de vista do desenvolvimento ético e intelectual da humanidade ${ }^{8}$.

O Brasil utiliza um meio termo, entre a democracia direta e representativa, quando possibilita a utilização dos mecanismos de democracia direta, o plebiscito e o referendo previstos no artigo 14 da Constituição Federal e já regulamentados pela Lei $\mathrm{n}^{\circ}$ 9.709, de 18 de novembro de 1998, de forma reservada. Dessa forma, teoricamente, os assuntos de maior relevância institucional podem ser decididos

\footnotetext{
${ }^{7}$ Art. 14, caput da Constituição da República Federativa do Brasil

${ }^{8}$ BOBBIO, Norberto. O futuro da democracia. Rio de Janeiro: Paz e Terra, 1986. p. 42.
} 
com uma maior participação dos eleitores de maneira a direcionarem ou ratificarem a atuação do Parlamento.

\section{DEMOCRACIA PARTICIPATIVA ATRAVÉS DE AUDIÊNCIAS PÚBLICAS}

O termo democracia participativa, bem como os conceitos formulados são relativamente recentes, pois foram cunhados no século $X X$, tendo surgido principalmente pelo desgaste da democracia representativa, embora as suas raízes remontem ao conceito de democracia direta clássica, praticada na Grécia antiga. A democracia participativa a que se refere este estudo não é aquela, mas sim a decorrente do princípio da participação popular estabelecido na Constituição Federal, e na legislação infraconstitucional.

Esta democracia participativa se consolida na medida em que os cidadãos utilizem todas as possibilidades participativas expressas na legislação e através delas ampliem ainda mais o dever dos governantes ouvir a sociedade e prestar contas de suas gestões.

A democracia participativa brasileira, garantida pelo principio da participação popular, prevê variadas formas de atuação do cidadão na condução política e administrativa do Estado. Dentre elas destaca-se a audiência pública, prevista constitucionalmente no âmbito da participação legislativa e em diversas normas infraconstitucionais.

Audiência pública é um processo de participação aberto à população, para que possa ser consultada sobre assunto de seu interesse e que participando ativamente da condução dos assuntos públicos, venha a compartilhar da administração local com os agentes públicos. Constitui-se em instrumento de legitimação das decisões, através de um processo democrático, onde constantemente a comunidade teria o direito de se manifestar sobre a melhor forma de administração da coisa pública e poderia controlar as ações dos governantes através de prestações de contas.

\subsection{Audiência pública enquanto instrumento de participação popular}


Esta modalidade participativa possibilita ao cidadão a obtenção de informações e conhecimento das ações da administração pública, bem como a possibilidade de avaliar a conveniência, a oportunidade e a intensidade de suas ações, na medida que estará administrando de forma compartilhada. É na verdade uma forma de efetivação dos princípios do Estado democrático e de direito, pois o cidadão ao interagir com a administração estará exercitando o poder que the é inerente.

A audiência pública, como espécie do gênero participação popular, constitui-se em importante vertente de prática democrática, tomada em sua plena concepção doutrinária, que é a possibilidade de acesso e exercício do poder. Ela se constitui em enorme meio de obtenção de informações, que capacitam o cidadão para uma participação de resultados, seja através da legitimação dos atos compartilhados com a administração, seja através de uma constante negociação democrática.

Atualmente vem crescendo o interesse dos políticos nacionais em praticar audiências públicas, por uma exigência legal, objetivando uma maior transparência de seus atos.

\subsection{Audiências públicas na Lei de Responsabilidade Fiscal, no Estatuto da Cidade e na Lei Orçamentária.}

Em 1789, já era reconhecido o direito da sociedade em receber prestação das contas dos agentes públicos, estando expressamente no art. XV da Declaração dos Direitos do Homem e do Cidadão, que "a sociedade tem o direito de exigir contas a qualquer agente público da sua administração" ${ }^{9}$.

A Lei Complementar 101/00 e a Lei 10.257/01 prevêem a realização de audiências públicas nos processos de elaboração e discussão dos Planos, da Lei de Diretrizes Orçamentárias e da Lei do Orçamento Anual, o que pode vir a concretizar no âmbito municipal, o princípio constitucional da participação popular. Pelo disposto na Lei de Responsabilidade Fiscal o poder executivo tem que ouvir a população no processo de elaboração daquelas leis ali especificadas, o que significa dizer que antes do envio do projeto de lei para o legislativo há 
necessidade de audiência pública para que a sociedade seja ouvida, porque a transparência e o controle popular na gestão fiscal é norma de caráter obrigatório.

Assim também, depois de enviados os projetos de leis ao poder legislativo, novamente a sociedade tem que ser chamada a participar, desta vez no âmbito deste poder, para debater com o parlamentar de como ele votará, se do modo decidido pela comunidade, ou conforme os seus interesses políticos e pessoais.

No Estatuto da Cidade a exigência se repete, com a diferença de que a obrigatoriedade de ouvir a comunidade é expressa, transformando-se em condição de validade para a aprovação das referidas leis pela Câmara Municipal.

Não foi por mera formalidade que foi inserida a realização de audiência públicas no capítulo que trata da transparência na Lei Complementar 101/00 e no de gestão democrática da cidade, na Lei 10.257/01, mas sim, porque o controle da gestão fiscal está intimamente ligado ao tema da moralidade administrativa e da gestão democrática, neste ponto, Odete Medauar afirma que "certo é que, mais efetivos se mostrassem os mecanismos de controle sobre a administração, menor seria o índice de corrupção" ${ }^{10}$.

É no município que o cidadão pode exercer plenamente a sua cidadania, no seu local de moradia é que poderá se iniciar um grande processo de transformação, através da participação nas decisões que lhe afetam diretamente e da fiscalização das ações administrativas dos governantes locais. Na medida em que avança e se consolida o nível de participação popular aumenta o grau de compreensão dos moradores sobre o funcionamento da máquina administrativa, elevando a sua consciência cidadã e o seu compromisso com as causas coletivas.

É, pois, dever do bom administrador dar efetividade às garantias legais de participação do cidadão na vida administrativa do seu governo, pois se o princípio da legalidade é dever do agente público, com muito mais razão a sua observância quando se trata do interesse público, e se este é indisponível, não está a decisão

\footnotetext{
${ }^{9}$ ALTAVILA, Jaime de. Origem dos direitos dos povos. 4. ed. São Paulo: Edições Melhoramentos, 1964. Pág. 218

${ }^{10}$ MEDAUAR, Odete. Direito administrativo moderno. 5 ed. São Paulo: Revista dos Tribunais, 2001. Pág. 369.
} 
na esfera da discricionariedade do agente, possibilitar ou não a participação, não se trata de uma faculdade e sim de um dever.

O prefeito que não incentiva e não garante a participação popular na sua administração, pratica crime de responsabilidade definido no art. $1^{\circ}$, XIV do Decreto-Lei no 201 de 27 de fevereiro 1967, porque está negando execução à lei, não só à lei, mas à própria constituição; incorre ainda em crime de improbidade administrativa, prevista no art. 11 da Lei 8429/92, porque está atentando contra os princípios da administração pública.

Sendo o princípio da participação popular garantia constitucional, e a audiência pública instrumento dessa participação, a sua previsão na Lei de Responsabilidade Fiscal e no Estatuto da Cidade transforma a sua realização em condição de validade para o processo legislativo que tenha por objeto os Planos, Lei de Diretrizes Orçamentárias e Lei do Orçamento Anual.

Ao analisar as contas anuais, dos poderes executivos, legislativos e judiciários, os Tribunais de Contas devem exigir a comprovação de que a sociedade teve a oportunidade de ser ouvida, de que há no município um efetivo meio de incentivo a participação popular, e que as audiências públicas previstas nesta lei e no Estatuto da Cidade são efetivamente realizadas.

A comprovação deve ser exigida porque a participação popular é princípio constitucional e condição obrigatória nos processos de elaboração e discussão das Leis Orçamentárias e Planos, nulificando o processo que não observar minimamente o dever de ouvir a sociedade. A não observância deste princípio vicia o processo de feitura da lei orçamentária, pois terá preterido formalidade essencial, pois se é certo que a participação popular é princípio constitucional, afronta-lo enseja a invalidação de qualquer ato praticado sem a sua observância.

Conforme afirma Bandeira de Melo:

Violar um princípio é muito mais grave que transgredir uma norma qualquer. A desatenção ao princípio implica ofensa não a um específico mandamento obrigatório, mas a todo o sistema de comandos. É a mais grave forma de ilegalidade ou inconstitucionalidade, conforme o escalão do princípio atingido, porque representa insurgência contra todo o sistema, subversão de 
seus valores fundamentais, contumélia irremissível a seu arcabouço lógico e corrosão da sua estrutura mestra ${ }^{11}$.

\section{CONCLUSÃO}

Este trabalho não pretende esgotar o assunto, porém a estudo permite concluir que a participação popular no controle da administração pública é própria do Estado Democrático de Direito, sendo decorrência natural deste modelo de Estado.

Na Constituição Federal há várias previsões de participação do cidadão na administração pública e a participação popular enquanto princípio constitucional é direito de participação política, de decidir junto, de compartilhar a administração, opinar sobre as prioridades e fiscalizar a aplicação dos recursos públicos e ao afirmar que o povo exerce diretamente o poder, entrega a este a possibilidade de se tornar membro efetivo do controle social da administração pública.

A democracia participativa se consolidará na medida em que os cidadãos utilizem as possibilidades participativas e através delas ampliem ainda mais o dever dos governantes ouvir a sociedade e prestar contas de suas gestões.

A audiência pública é um processo de participação aberto à população, para que possa ser consultada sobre assunto de seu interesse e constitui-se em instrumento de legitimação das decisões, através de um processo democrático real, onde constantemente a comunidade se manifesta sobre a melhor forma de ser administrada e controla a ação dos governantes.

O estudo revela que sendo o princípio da participação popular garantia constitucional e a audiência pública instrumento dessa participação, com previsão na Lei de Responsabilidade Fiscal e no Estatuto da Cidade, transforma a sua realização em condição de validade para o processo legislativo que tenha por objeto os Planos, Lei de Diretrizes Orçamentárias e Lei do Orçamento Anual.

Embora esteja nítido na legislação a garantia à participação popular no controle da administração pública, este estudo não buscou comprovar se esta participação está ocorrendo efetivamente.

\footnotetext{
${ }^{11}$ BANDEIRA MELLO, Celso Antonio. Curso de direito administrativo. 13 ed. São Paulo: Malheiros, 2001. Pág. 772
} 


\section{BIBLIOGRAFIA}

ALTAVILA, Jaime de. Origem dos direitos dos povos. 4 ed. São Paulo: Edições Melhoramentos, 1964.

AZAMBUJA, Darcy. Introdução à Ciência Política. 6.ed. Rio de Janeiro: Globo,1987.

BANDEIRA DE MELLO, Celso Antônio. Curso de direito administrativo. 13 ed. São Paulo: Malheiros, 2001.

BASTOS, Celso Ribeiro \& MARTINS, Ives Gandra. Comentários à Constituição do Brasil. $3^{\circ}$ vol. Tomo II. São Paulo: Saraiva, 1993

BOBBIO, Norberto. Estado, governo, sociedade - para uma teoria geral da política. 12. ed. São Paulo: Paz e Terra, 1999.

. O futuro da democracia. Rio de Janeiro: Paz e Terra, 1986.

BRASIL. Constituição (1988). Constituição da República Federativa do Brasil. promulgada em 5 de outubro de 1988. Brasília: Congresso Nacional, 1988.

BRASIL. Decreto-Lei no 201 de 27 de fevereiro 1967. Dispõe sobre a Responsabilidade dos Prefeitos e Vereadores, e dá outras Providências. Disponível em: <http://www.tse.gov.br/utilidades/download/legislacao/ dl_201_67.doc>. Acesso em: 20/07/2003.

BRASIL. Lei Complementar no 101, de 04 de maio de 2000. Estabelece normas de finanças públicas voltadas para a responsabilidade na gestão fiscal e dá outras providências. Brasília: Congresso Nacional, 2000.

BRASIL. Lei ${ }^{\circ} 8.429$, de 2 de junho de 1992. Disponível em:

<http://www.tce.am.gov.br/lei\%208429-92.pdf>. Acesso em 17/08/2004.

BRASIL. Lei $n^{\circ} 9.709$, de 18 de novembro de 1998. Regulamenta a execução do disposto nos incisos I, II e III do art. 14 da Constituição Federal. Disponível em: <http://www.presidencia.gov.br/ccivil_03/LEIS/L9709.htm>. Acesso em: 07/02/2003.

BRASIL. Lei $n^{0} 10.257$, de 10 de julho de 2001. Regulamenta os arts. 182 e 183 da Constituição Federal, estabelece diretrizes gerais da política urbana e dá outras providências. Disponível em: <http://www.unama.br/institucional/proreitorias/pppe/ supes/MeioAmbiente/Documentos/Lei\%2010257\%202001.doc>. Acesso em: 15/09/2003.

BULOS, Uadi Lammêgo. Constituição Federal anotada. 4. ed. São Paulo: Saraiva, 2002. 
CARMAGNANI, Marcelo. El Federalismo Historia de una Forma de Gobierno, Federalismos latinoamericanos: México/Brasil/ Argentina. Coordenador Marcello Carmagnani, Ed. Fondo de Cultura Económica México, 1993.

CARRION, Eduardo Kroeff Machado. Apontamentos de direito constitucional. Porto Alegre: Livraria do Advogado, 1997. pp. 83/84

CASTRO, Flávio Régis Xavier de Moura e (org). Lei de Responsabilidade Fiscal: abordagens pontuais: doutrina, legislação. Belo Horizonte: Del Rey, 2000.

DALLARI, Dalmo de Abreu. O que é participação política. São Paulo: Abril Cultural: Brasiliense, 1984

DI PIETRO, Maria Sylvia Zanella. Participação popular na administração pública. Revista de direito administrativo. Rio de Janeiro: Editora, 1994, n. 191.

FREITAS, Juarez. O Controle social no orçamento público. Interesse Público. São Paulo: Notadez , 2001. no 11.

GIL, Antônio Carlos. Como Elaborar Projetos de Pesquisa. 3 ed. São Paulo: Atlas, 1996.

GRUPPI, Luciano. Tudo começou com Maquiavel - As concepções de Estado em Marx, Engels, Lênin e Gramsci. 7 ed. Porto Alegre: L\&PM, 1989

KELSEN, Hans. Teoria Geral do Direito e do Estado. Título original: General Theory of Law and State. Tradução de Luís Carlos Borges. $2^{\mathrm{a}}$ edição. São Paulo, Martins Fontes, 1992.

LIJPHART, Arend, As Democracias Contemporâneas. Ed. Gradiva Publicações Lisboa, 1989.

MANCUSO, Rodolfo de Camargo. Ação popular - Proteção do erário, do patrimônio público, da moralidade administrativa e do meio ambiente. 3 ed. São Paulo: Revista dos Tribunais, 1998.

MAQUIAVEL, Nicolau. O príncipe. Tradução. introdução e notas de Antonio D’Elia. São Paulo: Cultrix, 1987.

MEDAUAR, Odete. Direito administrativo moderno. 5 ed. São Paulo: Revista dos Tribunais, 2001.

MELO, Mônica. Plebiscito, referendo e iniciativa popular - mecanismos constitucionais de participação popular. Porto Alegre: Fabris Editor, 2001.

OLIVEIRA, Gustavo Henrique Justino de. As audiências Públicas e processo administrativo. Revista de informação legislativa. Brasília: Senado Federal, 1997, n. 135. 
ROUSSEAU, Jean Jacques. Do Contrato Social. Tradução, introdução e notas de Edson Bini. São Paulo: Edipro, 2000.

ZANCANER, Weida. Da convalidação e da invalidação dos atos administrativos. São Paulo: Revista dos Tribunais, 1990. 